\title{
El debate sobre el divorcio en el catolicismo argentino. La intervención de los políticos democristianos y la prensa católica
}

\author{
The debate of the divorce in Argentine Catholicism. The intervention of Christian Democrat politicians and the \\ Catholic press
}

Mariano David Fabris

Centro de Estudios Históricos, Universidad Nacional de Mar del Plata, CONICET, Argentina marianofabris76@gmail.com

\begin{abstract}
RESUMEN:
El objetivo que perseguimos en este trabajo es analizar las posiciones que asumieron diferentes actores católicos frente al debate sobre el divorcio vincular en la Argentina de la década de 1980. El análisis hace foco en la prensa católica, específicamente en las revistas Esquiú, Cabildo y Criterio, y en el Partido Demócrata Cristiano. Se considera que la falta de registro de las diferentes miradas que convivieron en el catolicismo se debe a la escasez de investigaciones sobre el tema, pero, fundamentalmente, a factores y representaciones propios del contexto en el que se debatió el divorcio. Influyen, en este sentido, discursos que plantearon la cuestión del divorcio como una disputa irreductible entre laicistas y católicos, alimentando un sentido común extendido y el celo puesto por la jerarquía eclesiástica para obturar la emergencia de voces alternativas que cuestionaron la campaña antidivorcista desplegada por los obispos.

Palabras Clave: Divorcio, Catolicismo, Secularización, Democracia Cristiana, Prensa católica.
\end{abstract}

\section{Abstract:}

The objective that we pursue in this article is to analyze the positions assumed by different catholic actors around the debate on divorce in Argentina in the 1980s. The analysis focuses on the Catholic press, specifically in the Esquiu, Cabildo and Criterio magazines, and in the Christian Democratic Party. It is considered that he lack of registration of the different views that coexisted in Catholicism is due to the scarcity of research on the subject, but, fundamentally, to factors and representations of the context in which divorce was debated. Influence, in this sense, discourses that raised the issue of divorce as an irreducible dispute between secularists and catholics feedingan extended commonsense and thezeal placed by the ecclesiastical hierarchyto block the emergence of alternative voices that questioned the antidivorcist campaign displayed by the bishops.

KeYwords: Divorce, Catholicism, Secularization, Christian Democracy, Catholicpress.

\section{INTRODUCCIÓN ${ }^{1}$}

El objetivo que perseguimos en este trabajo es analizar las posiciones que asumieron diferentes actores dentro del catolicismo frente al debate sobre el divorcio vincular en la Argentina de la década de 1980. En un universo amplio, nos centramos en tres referentes de la prensa católica -las revistas Esquiú, Criterio y Cabildo- y en el Partido Demócrata Cristiano (PDC).

La reforma que introdujo el divorcio vincular en la legislación argentina y los debates que se generaron a su alrededor fueron abordados en el marco de diferentes líneas de investigación. Quienes se interesaron por el rol de los obispos luego del retorno de la democracia encontraron allí un conflicto que exponía con nitidez $l$ as dificultades de la jerarquía católica para integrarse en el nuevo escenario político (Ezcurra, 1988; Esquivel, 2004; Bonnin, 2006). Esta línea de indagación identificó actitudes diversas y, en ocasiones, contrapuestas en un Episcopado en el que convivían, detrás del común rechazo al divorcio, quienes convocaban a una especie de cruzada contra los promotores de la reforma junto a los partidarios de concentrar las energías en la formación de los católicos. En trabajos anteriores (2011) profundizamos 
en el análisis de este proceso y señalamos que las actitudes de los obispos no sólo fueron diversas sino que además variaron en el trascurso del debate. La cuestión del divorcio fue recuperada también, aunque no analizada en profundidad, por los estudios que se interesaron en las cuestiones de género y en el proceso de ampliación de derechos a partir del retorno de la democracia. Desde esta perspectiva, la aprobación de la rehabilitación nupcial para las parejas separadas fue considerada un paso fundamental en la "ciudadanización de las relaciones personales" (Pecheny, 2010: 90), proceso que se prolongaría más tarde con el matrimonio igualitario en 2010 (Giordano, 2014). Finalmente, abordajes periodísticos o testimoniales centrados en el gobierno de Raúl Alfonsín o en su trayectoria política situaron al debate sobre el divorcio en la trama de una lucha anticorporativa en la que se habría enfrascado el gobierno (Muiño, 2013; Mc Adam, Sukup y Katiz, 1999).

Desde puntos de partida diferentes, estos abordajes permiten reconstruir el proceso en sus trazos generales. Sin embargo, la coyuntura abierta por la discusión del divorcio también resulta pertinente para analizar las relaciones de poder y las disputas que recorren el catolicismo, y que adquieren mayor claridad cuando lo que está en debate son cuestiones estratégicas para la Iglesia. En este sentido, si bien los estudios centrados en la jerarquía eclesiástica recuperaron, como señalamos, las tensiones que cruzaban el Episcopado, prestaron mucha menor atención a otras voces que pugnaban por intervenir en el debate. En el caso de los estudios de género, las disidencias en el catolicismo fueron aspectos poco registrados en una lectura que tendió a identificar en la Iglesia un núcleo de resistencia bastante compacto. Esta perspectiva se acentúa más en el caso de las reconstrucciones periodísticas.

Históricamente, los países que contaban con una larga y viva tradición católica atravesaron por ciertas turbulencias a la hora de avanzar en alguna modificación en la legislación familiar. Por esta razón, los sociólogos e historiadores de la religión encontraron en este ámbito uno de los nudos problemáticos más relevantes para analizar la construcción de la laicidad y la dinámica de la secularización, entendida como “el proceso de reorganización permanente del trabajo de la religión” (Hervieu-Léger, 2004: 122-123). Los ajustes que se producen en la articulación entre la dinámica social y la de las instituciones religiosas conllevan también cambios en las relaciones de poder en el interior de la configuración católica. En estos términos, el catolicismo no se presenta como un cuerpo encolumnado tras su jerarquía sino como un espacio conflictivo en el que conviven matices y diferencias profundas que, al ser recuperadas, exponen una imagen mucho más compleja, conflictiva y tensionada de la Iglesia.

En la Argentina el divorcio fue, ciertamente, uno de los temas más conflictivos en las relaciones políticoeclesiásticas durante la década de 1980 y quedó asociado a una campaña de oposición virulenta liderada por algunos obispos que, además de movilizarse y convocar a los laicos, amenazaron a los legisladores con excomulgarlos y articularon un discurso que pronosticaba una especie de cataclismo social si se modificaba la legislación familiar. Sin embargo, no fue la de la jerarquía la única voz que se manifestó en el debate, razón por la cual consideramos que su comprensión, más allá de los avances logrados, requiere todavía de la incorporación de otros actores. El coro de voces que reconstruiremos pone en primer plano a la opinión pública que había tomado fuerza en el catolicismo en los años previos al Concilio Vaticano II, pero que durante la última dictadura militar se vio limitada drásticamente, al menos en algunas de sus expresiones, por el contexto represivo. Cada uno de los actores analizados expresó, a través de sus posiciones en el debate del divorcio, concepciones más amplias sobre la democracia, la Iglesia y la autoridad de la jerarquía eclesiástica en el contexto postdictatorial.

Dentro del universo de publicaciones católicas existentes en la década de 1980 -mucho más acotado que en las etapas previas- seleccionamos las revistas Esquiú, Criterio y Cabildo. La muestra es diversa ya que se trata de publicaciones que presentan diferencias sustanciales en términos políticos, teológicos, editoriales, empresariales y en sus vínculos con la jerarquía eclesiástica. Además, estas revistas recibieron un interés muy 
disímil en las investigaciones previas. Esquiú se comenzó a publicar en 1960 luego de la desaparición de El Pueblo, el diario católico más importante hasta entonces (Lida, 2012). Agotado el modelo editorial del viejo periódico, en un contexto de modernización de la prensa Esquiú pretendió brindar un producto remozado, una revista de actualidad dirigida a toda la familia, con secciones específicas para cada integrante. De todas maneras, ese perfil moderno convivió con un discurso que lo era en mucho menor medida (Fabris, 2013). Si bien su caso fue objeto de abordaje desde el análisis del discurso (Zaccari, 2004 y 2005) y en torno a algunas coyunturas específicas (González, 2012; M. Saborido, 2013; Fabris, 2012), no despertó demasiado interés, a pesar de que fue, al menos en las décadas de 1960 y 1970, una de las revistas con mayor circulación

en el catolicismo argentino. ${ }^{2}$ El caso de Criterio es diferente ya que su presencia destacada en la cultura intelectual católica la convirtió en un objeto privilegiado entre los estudios sobre el catolicismo argentino (Acha, 2001; De Ruschi Crespo; 1998; Rapalo, 1990; Lida, 2015; Lida y Fabris, 2019). En su trayectoria, iniciada en 1928, se destacó la búsqueda de una relativa autonomía con respecto a la jerarquía católica, en particular desde fines de los años cincuenta, y su cuestionamiento a la simbiosis entre Nación y catolicismo que era dominante en la Iglesia argentina. En la década de 1980 mostró cierta apertura ante el retorno de la democracia y comprendió que era necesario debatir sobre el rol que había jugado la Iglesia en la política argentina (Fabris, 2019). La revista Cabildo se comenzó a publicar en mayo de 1973 bajo la dirección de Ricardo Curutchet y rápidamente se erigió uno de los principales exponentes del nacionalismo católico (Saborido, 2011; Orbe, 2009; Rodríguez, 2011; Borrelli y Lanfranco, 2012). También se la identificó, dada la prevalencia de una particular concepción de la religión como principio dador de sentido a la Nación, como la principal publicación del "tradicionalismo católico" (Cersósimo, 2014). Saborido considera que el pensamiento expresado en las páginas de la revista se puede definir como una "teología política” en la medida en que se trató de un proyecto intelectual que buscó legitimar su praxis política en una doctrina religiosa. ${ }^{3}$

En cuanto al PDC, la bibliografía que lo abordó es relativamente escasa y si bien su conformación fue considerada en el contexto de los enfrentamientos entre Perón y la Iglesia que precedieron al golpe de Estado de 1955 (Caimari, 1995; Bianchi, 2001) y en el marco del proceso de secularización interna que vivió la Iglesia entre las décadas de 1950 y 1960 (Zanca, 2013: 181-182), sus vínculos con el catolicismo fueron poco considerados para las décadas siguientes (Fabris, 2018).Los dirigentes del PDC se definían como cristianos, pero no confesionales, y construían su espacio de acción a través de una distinción entre lo político y lo religioso. Sin embargo, los vasos comunicantes con la Iglesia -en cuyas instituciones muchos de sus dirigentes se habían formado- ${ }^{4}$ fueron fluidos y se reprodujeron con diferente intensidad según los contextos políticos y eclesiales. En este sentido, durante la última dictadura militar los dirigentes del PDC buscaron legitimidad para su endeble posición en los documentos episcopales y en las intervenciones de obispos que, como el arzobispo de Santa Fe Vicente Zazpe, tenían presencia habitual en los medios de comunicación (Fabris, 2018). En términos generales, pensamos que resultaría difícil comprender la trayectoria del partido, su carácter minoritario, las dificultades para representar a los cristianos argentinos, etc., sin tener en cuenta el lugar que la Iglesia y su jerarquía tuvieron históricamente en la política argentina y las estrategias que los obispos desarrollaron en búsqueda de apoyo para sus intereses. Partiendo de estas consideraciones, su inclusión en un análisis que apunta a reconstruir algunos de los debates que cruzaban el catolicismo luego del retorno de la democracia resulta relevante

El artículo se compone de tres partes. En la primera, abordamos la actitud asumida por el Episcopado y sus figuras más visibles frente a la cuestión del divorcio. En segundo término, ampliamos el panorama incorporando la prensa católica a través del análisis de los posicionamientos de Esquiú, Cabildo y Criterio. En el final, analizamos las respuestas que ofrecieron a esta cuestión los dirigentes democristianos. 


\section{LA JERARQUÍA CATÓLICA Y EL DIVORCIO VINCULAR}

Entendemos que, desde el punto de vista de las posiciones asumidas por los obispos, es posible diferenciar dos etapas en el proceso de aprobación del divorcio. La primera se inició con el retorno democrático y la aparición de los primeros proyectos de divorcio vincular y se cerró con la recomendación de la Comisión Permanente de la Conferencia Episcopal Argentina (CEA) para que se sancionara a los diputados que habían votado favorablemente el divorcio en agosto de 1986. Durante esta etapa se produjo un paulatino aumento de la tensión entre la Iglesia y el poder político que, a mediados de 1986, adquirió el carácter de un profundo enfrentamiento y repercutió al interior del Episcopado. La segunda etapa se extendió entre los últimos meses de 1986 y la aprobación definitiva del divorcio en junio de 1987, y estuvo caracterizada por una moderación de los enfrentamientos y por una mayor predisposición episcopal a la construcción de consensos con los representantes políticos y entre los propios obispos. A la luz de esta dinámica, es posible considerar que, desde el punto de vista de la ampliación de los derechos ciudadanos, la aprobación del divorcio fue una ruptura que, al mismo tiempo, alteró las relaciones entre el poder político y el eclesiástico y obligó a la jerarquía de la Iglesia a reconsiderar sus estrategias de intervención en defensa de sus intereses. Sin embargo, en esta última dimensión, más que de una ruptura deberíamos hablar de una reconfiguración de las relaciones políticoeclesiásticas que formaban parte de un pasado que el alfonsinismo había prometido alejar de la frontera política construida desde la campaña electoral de 1983 (Aboy Carles, 2001). El divorcio, entonces, anunció una agenda de temas en debate en el proceso de ampliación de derechos, pero también contuvo algunas lógicas que se constituirían en obstáculos para futuras reformas.

Partiendo de estos presupuestos, se podrá comprender que la actitud de los obispos ante el divorcio durante los años previos a su sanción no fue lineal ni uniforme, implicó matices y generó disputas. No hubo una única actitud dentro de la jerarquía católica y lo que predominó fue la constitución de consensos mínimos que garantizaron un margen de autonomía para que cada obispo abordara el tema según su parecer. De todas maneras, incluso con este margen de maniobra, los cruces entre los obispos fueron frecuentes. La voz cantante en el debate recayó en el Secretariado Episcopal para la Familia presidido por Emilio Ogñenovich, obispo de Mercedes. Ogñenovich, ordenado obispo en 1979, descolló rápidamente como un obispo locuaz, poco atento a los límites -formales- que imponía su investidura y reacio a cualquier gesto de adaptación al nuevo contexto político y social. ${ }^{5}$

El activismo de Ogñenovich en torno al tema del divorcio se puede rastrear bastante antes del retorno de la democracia, ya que bastó que el final de la dictadura emergiera como un horizonte cercano para que el obispo de Mercedes diera inicio a su lucha "en defensa de la familia". Previamente a las elecciones de octubre de 1983 sostuvo:

Sepan, cuando pretenden atentar contra el matrimonio y la familia, que sobran corazones valientes, sobran católicos con capacidad de héroes para defender lo que es pilar básico de la sociedad argentina: la familia y el matrimonio. No tenemos cañones, ni balas, ni ejércitos, pero tenemos la voz firme, las convicciones profundas, tenemos una fe católica, apostólica y romana, que nos empuja a dar la vida si es necesario, en defensa de los sagrados principios de la persona humana y de nuestras convicciones religiosas, que son las de la inmensa mayoria de los argentinos. ${ }^{6}$

El tono de los discursos de Ogñenovich no parecía corresponderse con la importancia del divorcio en el contexto preelectoral. A decir verdad, eran otros los temas que despertaban mayor preocupación y la cuestión se mantuvo fuera de la agenda de los partidos mayoritarios. Pero esta ausencia no se debía únicamente a que se trataba de un tema secundario en ese contexto sino también a que los partidos estaban más preocupados por ganarse el favor y el apoyo -o al menos la prescindencia- de los obispos que a abrir brechas entre los actores que podían colaborar en la retirada militar (Fabris, 2011). Ogñenovich percibió el cálculo político en la ausencia del tema, dio por seguro que el divorcio sería objeto de debate una vez que asumiera el nuevo gobierno y por ello denunció a quienes pretendían "destruir a la familia argentina”. En algo Ogñenovich no 
se equivocaba: desde el verano de 1984 los proyectos que incluían el divorcio vincular comenzaron a ingresar al Congreso. Para 1986, cuando finalmente se inició el debate legislativo, se había acumulado una veintena de propuestas.

En esta primera etapa se podrían diferenciar, a su vez, dos períodos. Durante el primero, que se extendió entre el retorno de la democracia y fines de 1985, la jerarquía centró su posición frente al tema a partir de documentos, declaraciones públicas, entrevistas y cartas pastorales, mientras que el activismo quedó más circunscripto a las iniciativas de Ogñenovich. ${ }^{7}$ En un segundo período, que se extiende a lo largo de 1986, el activismo fue generalizado y se alcanzaron los momentos más álgidos en la campaña.

Durante los primeros dos años del retorno de la democracia, entonces, las homilías, los mensajes pastorales y algunos documentos colectivos de los obispos explicitaron el rechazo episcopal al divorcio. En términos generales, las invocaciones de los obispos en forma colectivatuvieron un tono más moderado que cuando se pronunciaban individualmente ya que, aunque no faltaban advertencias fuertes, la necesidad de lograr consensos entre los obispos imponía ciertos límites. La idea de que los partidos traicionaban al electorado al proponer una reforma ausente en la campaña fue bastante recurrente. Junto a esta acusación, se enumeró la larga lista de problemas que provocaría la nueva legislación y se enfatizó en la situación de los hijos. El núcleo más activo de obispos, además, mostró especial preocupación por los "católicos divorcistas". El castigo que recibió José Amado Aguirre, un sacerdote cordobés que se había manifestado favorable al divorcio, sentó un precedente temprano de cuál sería la respuesta de la jerarquía ante las disidencias. ${ }^{8}$ Aun en un contexto postconciliar en el cual los cánones de autoridad vigentes se diferenciaban mucho de los predominantes durante la primera mitad del siglo XX, algunos obispos consideraron más serio el desafío de los "católicos divorcistas" que el divorcio mismo.

Paralelamente, los mensajes de Ogñenovich recorrieron caminos mucho más polémicos, cuestionando el proyecto de ley, las políticas del gobierno y hasta la democracia recuperada. El 25 de mayo de 1984 sostuvo, en una homilía en la Basílica de Lujan, que existía "una campaña muy bien orquestada en la radio y la televisión, en los diarios y en las revistas -especialmente en las panfletarias y pornográficas- contra la unidad e indisolubilidad matrimonial". " Era, para el obispo, como "si fuerzas del averno se hubieran desatado contra el matrimonio y la familia renegando de las tradiciones nacionales que hicieron grande a la Argentina". ${ }^{10}$

A lo largo de1986 los consensos dentro del Episcopado se pusieron a prueba.La inminencia del tratamiento legislativo disparó el activismo de muchos obispos y grupos católicos, pero nunca se logró articular una campaña a nivel nacional. Mientras en algunas diócesis los obispos se pusieron a la cabeza de movilizaciones y llevaron adelante encuentros y demostraciones públicas, en otras sólo hubo charlas o alguna jornada de concientización dedicada a los fieles sobre el sentido cristiano del matrimonio. Hubo diócesis, finalmente, en las que no se registraron actividades relevantes en relación con el divorcio.

Durante esta etapa las apariciones de Ogñenovich se multiplicaron. El obispo incluso fue invitado a exponer antes una comisión de legisladores de quienes, de todas maneras, no aceptaría preguntas. ${ }^{11}$ A decir verdad, el núcleo irreductible de su posición negaba cualquier potestad de los políticos para legislar sobre el matrimonio en la medida enque este formaba parte de la ley natural y quedaba sólo al arbitrio de Dios.

El éxito de la estrategia de confrontación del obispo -y particularmente su capacidad para presionar a los legisladores- dependía, en buena medida, de que, en el contexto de una sociedad movilizada desde el final de la dictadura, el rechazo al divorcio también fuera convocante. Sin embargo, desde muy temprano quedó en evidencia que sólo los católicos más comprometidos saldrían a la calle "en defensa de la familia" y que, probablemente, sólo unos pocos lo harían por propia iniciativa. Desde el punto de vista cuantitativo, los católicos movilizados no constituían una fuerza capaz de conmover a los legisladores y parecía muy difícil que el divorcio se definiera en la calle. En todo caso, quedaba por ver si las movilizaciones eran suficientes para dirimir los conflictos entre los obispos que habían empezado a ganar estado público. En este sentido, algunos miembros de la jerarquía se habían mostrado contrarios a la exacerbación del conflicto. Ya en septiembre de 
1985, Antonio Quarracino, obispo de Avellaneda y presidente del CELAM, definió la actitud que la Iglesia debía adoptar frente al tratamiento del divorcio:

su deber es afirmar con claridad su doctrina; en segundo lugar, ha de ser más exigente, según las normas de una pastoral realista y comprensiva, en lo que se refiere a la administración del santo sacramento del matrimonio. Por otra parte, estimo que no se debe convocar a la gente a las calles para manifestaciones de repulsa o aprobación. ${ }^{12}$

Lo cierto es que Ogñenovich no ahorró esfuerzos y creó una red de grupos que se encargaron de organizar encuentros, jornadas y editar folletos en los cuales el divorcio aparecía asociado a toda una gama de "males sociales". Pornografía, "destape", drogadicción, erosión de las tradiciones y de las instituciones básicas de la sociedad -Iglesia y FF.AA.- problemas sociales, crisis económica, etc.: todo se podía vincular con el divorcio. Según rezaba una publicidad:

Hoy usted tiene la posibilidad de peticionar:para que la pornografía no nos agreda más; para que la televisión no invada nuestros hogares con programas disolventes; para que terminen los crimenes impunes producidospor el aborto; para que se respete la libertad de los padres a educar a sus hijos; para que no existan padres sin poder trabajar por falta de fuentes laborales; para que el salario sea digno para sostener a la familia; para que las familias tengan derecho a su propia vivienda; para que las familias no sean divididas por el flagelo del divorcio; para que no haya familias necesitadas del pan. ${ }^{13}$

En abril de 1986 la labor de Ogñenovich recibió un fuerte respaldo institucional al ser confirmado en el cargo y el secretariado que presidía fue elevado a Comisión Episcopal para la Familia. Este apoyo, de todas maneras, no despejó las tensiones entre los obispos, que las hubo y se expusieron, a veces, de manera inusitada. Laguna, opositor al tono de la campaña desplegada por Ogñenovich, sostuvo que los caminos eran "iniciar una guerra santa o proclamar con firmeza y humildad nuestras convicciones". ${ }^{14}$

El hecho más importante de la campaña desplegada fue una movilización a la Plaza de Mayo bajo el lema "La familia es garantía y esperanza de nuestra Patria". ${ }^{15}$ Para esa ocasión la Virgen de Lujan fue llevada en procesión desde la basílica, hecho que sólo registraba un antecedente a finales de la década de 1950. La concurrencia fue variopinta y si bien el grupo más importante estaba integrado por estudiantes de colegios confesionales, no faltaron sectores de la extrema derecha o vinculados a la última dictadura militar, como FAMUS, la Alianza Libertadora Nacionalista o la Cruzada Cristiana Anticomunista,ni dirigentes oportunistas que se acoplaron al reclamo de la Iglesia renegando de anteriores posicionamientos. Este fue el caso del gobernador tucumano Fernando Riera, quien había votado el divorcio en 1954 pero que, en el nuevo escenario, decretó la adhesión oficial de su provincia a la marcha. ${ }^{16}$ Posteriormente, la movilización callejera se replicó, con éxito disímil, en varias ciudades del interior. ${ }^{17}$

Si tanto esfuerzo desplegado tenía el objetivo de cerrar el paso al divorcio vincular en Argentina, el resultado no pudo ser más decepcionante. En agosto de 1986 la Cámara de Diputados le dio media sanción al divorcio por amplio margen. En respuesta a la media sanción, varios obispos se pronunciaron contra los diputados y la Comisión Permanente de la CEA, como señalamos, recomendó que se prohibiera a los legisladores católicos que habían votado favorablemente el divorcio la participación en la Sagrada Eucaristía si no existía previamente un arrepentimiento público. ${ }^{18}$ Esta decisión alimentó aún más las tensiones. En los medios arreciaron las críticas a la CEA y las diferencias entre los obispos alcanzaron un nivel de exposición demasiado alto para la imagen de unidad que la jerarquía eclesiástica cultivaba con más celo que éxito. Algunos de los obispos que con mayor fuerza se habían opuesto al tono predominante de la campaña antidivorcista redoblaron sus críticas y apuntaron contra aquellos prelados que durante la dictadura habían tenido actitudes complacientes con el gobierno militar y que nunca se habían manifestado con igual claridad frente a las violaciones a los derechos humanos. Jaime de Nevares, obispo de Neuquén, se preguntó por qué quienes promovían las sanciones "no tomaron una actitud similar frente a los muchos militares y civiles que durante el régimen del proceso cometieron terribles violaciones a los derechos humanos. [cursiva en el original]”19 
Llegó un momento en el que el fuego cruzado entre los obispos pasó a tener más repercusión que la aprobación del divorcio en sí. Frente a esta situación, el presidente de la CEA, el siempre contemporizador Raúl Primatesta, sostuvo:

En más de una ocasión, frente a los cambios, a dificultades nuevas, a renovados planteos pastorales, a opinables enfoques y apreciaciones o fuimos mal interpretados, o no supimos dar la imagen de una unidad que ciertamente existe en nuestro corazón de pastores. ${ }^{20}$

Estas declaraciones marcan el inicio de la segunda etapa en el proceso de aprobación del divorcio. Desde entonces la jerarquía modificó su actitud, buscó bajar los decibeles de las manifestaciones públicas y planteó el objetivo más modesto -y probablemente más realista- de posponer la aprobación definitiva para luego de la visita de Juan Pablo II, programada para abril de 1987. Sobre esta base buscó y logró el consenso de una dirigencia política que tampoco estaba interesada en mantener abiertos focos de conflicto. Un signo bastante elocuente del cambio en la estrategia episcopal fue la desaparición de escena de Ogñenovich. ${ }^{21}$ De esta manera, la aprobación del divorcio se dio en un contexto completamente diferente, tal como quedó expuesto en el mensaje de la Comisión Ejecutiva de la CEA con motivo de la sanción de la nueva normativa por parte del Senado. Allí, si bien reafirmaron que la ley comprometería el futuro de la familia argentina, sostuvieron que esa era su creencia y que eran " conscientes del respeto a la competencia propia de los señores legisladores". ${ }^{2}$

Como se señaló (Fabris, 2011), los meses que separan el tratamiento legislativo en ambas cámaras son de una enorme riqueza para comprender los ajustes que debió realizar la jerarquía católica ante los cambios que se venían produciendo en la sociedad y que, como no podía ser de otra manera, impactaban entre los laicos y también en el clero. Fue un tiempo en el cual los obispos comprendieron, aceleradamente, que los discursos de cruzada y las representaciones de la Iglesia como cuerpo homogéneo que marcha bajo la guía de la jerarquía ya no tendrían éxito.

\section{Los católicos y el divorcio: Esquiú, Cabildo, Criterio y la diversidad de voces EN CONFLICTO}

En el catolicismo argentino convivieron posicionamientos diversos en relación con la cuestión del divorcio. Hubo sectores que apoyaron sin fisuras la campaña desarrollada por Ogñenovich y quienes, en forma más o menos explícita, plantearon dudas sobre su éxito o sobre la validez de los argumentos episcopales en el contexto de una democracia pluralista. No faltaron voces, incluso, que criticaron a los obispos por una supuesta tibieza en la defensa de los valores católicos y reclamaron otras respuestas ante los desafíos que planteaba el nuevo contexto político. Más allá de los fundamentos a los que se recurrió para sostener tales posiciones, lo relevante es señalar que estas se manifestaron dándole forma a una configuración disputada y profundamente interpelada por nuevos discursos y representaciones de la sociedad y la política.

\section{La revista Esquiú: una voz oficiosa}

Durante los últimos años de la dictadura militar Esquiú buscó afianzarse como voz oficiosa de la jerarquía. Por esa época la publicación atravesaba una situación económica complicada, su circulación no hacía más que reducirse y junto a ella, seguramente, también la cantidad de anunciantes. ${ }^{23}$ En ese marco, ser una correa de transmisión de los discursos episcopales resultó una alternativa atractiva, aunque no sencilla dadas las tensiones que existían entre los obispos. Para el Episcopado, la prensa católica masiva no había sido una prioridad, en la medida en que era más importante tener acceso a los grandes medios de comunicación; sin embargo, la necesidad de reposicionarse frente a los desafíos del contexto político podía convertir a Esquiú en un medio de comunicación eficaz para llegar a los laicos. La revista fue importante, por ejemplo, 
en la difusión de una imagen favorable de los obispos, con la que se pretendió hacer frente a las críticas por la labor de la Iglesia durante la dictadura (Fabris, 2015) y también durante el Congreso Pedagógico Nacional, cuando fue recomendada por la CEA como fuente de información y lectura casi obligatoria para los católicos que participaron.

Ogñenovich fue el más interesado en aprovechar las posibilidades que ofrecía uno de los pocos medios de comunicación masivos con los que contaba la Iglesia. En 1983 Esquiú comenzó a publicar un suplemento llamado "En Familia", que era producido directamente por el Secretariado Episcopal dirigido por Ogñenovich. Desde sus páginas, quien sería llamado "el obispo de la familia" ${ }^{24}$ solía lanzar sus diatribas contra los políticos y arremeter con un discurso apocalíptico que, como vimos, era su marca registrada.

Si bien poco después el suplemento dejó de publicarse, la revista se puso a disposición de las iniciativas del obispo y brindó un espacio privilegiado a sus declaraciones y mensajes contra el divorcio, e incluyó reseñas históricas de anteriores debates, estudios y testimonios de laicos comprometidos. Ya en 1985, cuando se debatió la modificación en el régimen de patria potestad, Esquiú se hizo eco de los reclamos episcopales y calificó la nueva normativa como un ataque a la familia, en particular por la igualación de los derechos de los hijos nacidos dentro del matrimonioy fuera de él. ${ }^{25}$ Agustín Luchía Puig, sacerdote y uno de los fundadores de la revista, no dudó en calificar al divorcio como "cáncer de la sociedad", ${ }^{26}$ mientras que Luis Eduardo Luchía Puig, director de la revista, asoció el divorcio al aumento de la delincuencia, la drogadicción y la pornografía. ${ }^{27}$ En la etapa más álgida del conflicto, el del divorcio fue el tema excluyente en las páginas de Esquiú. Las notas se multiplicaron en forma de columnas de opinión, entrevistas, reproducción de documentos oficiales, publicidad de encuentros y charlas, siempre con la denuncia hacialos políticos y de una, supuesta, campaña anticatólica como telón de fondo. La revista hizo un seguimiento pormenorizado de los preparativos para la movilización a la Plaza de Mayo, publicó las declaraciones de la organización, el cronograma y el recorrido de la procesión que portaría a la Virgen. La movilización fue cubierta con espectacularidad: nueve páginas condiscursos, testimonios y fotos. ${ }^{28}$ En su columna, el director de la revista sostuvo:

No me importa si eran cien mil o cincuenta mil, la plaza estaba colmada de gente convocada por el amor. Nuevamente el trigo habia triunfado sobre la cizaña, y pensé en una oración del Papa, donde evoca la imagen de la Virgen aplastando con el pie la cabeza de una serpiente. ${ }^{29}$

Esquiú, como señalamos, fue una herramienta a través de la cual los obispos que lideraron la campaña contra el divorcio convocaron a los laicos y trataron de establecer los marcos de su participación. En este sentido, las páginas de la revista pusieron énfasis en desacreditar cualquier posición que, en el catolicismo, cuestionara la campaña liderada por Ogñenovich o propusiera salidas de compromiso. Así, apelaron al arzobispo de Santa Fe, Edgardo Storni, para recordar que

ningún católico en comunión con la Iglesia puede afirmary menos propugnar la bondad y validez del divorcio vincular. Cualquier aclaración o precisión de fondo respecto de esta verdad, que afecta a la misma catolicidad de los creyentes, corresponde a los únicos maestros y legisladores puestos por el Señor en su Iglesia, es decir, al Papa y a los obispos. ${ }^{30}$

La importancia que Esquiú le atribuyó al divorcio varió de acuerdo con las estrategias de la jerarquía eclesiástica. Por ello, cuando el Episcopado privilegió la búsqueda de algún tipo de acuerdo con el poder político y bajó los decibeles del enfrentamiento, el tema, y Ogñenovich como su principal promotor, perdieron espacio en la revista. Lo que tal vez no haya sido percibido en ese momento es que por las mismas razones que la figura de Ogñenovich se apagaba, la revista dejaba de ser relevante en las estrategias de la CEA. Moderado el conflicto frente al cual una parte de la jerarquía eclesiástica se había comportado defendiendo una fortaleza atacada, se imponía volver a los tiempos de paz. Tal vez no sea casualidad que unos pocos meses después de aprobado el divorcio, la familia Luchía Puig vendía la revista. 


\section{La mirada de Criterio: la necesidad de delimitar ámbitos}

La posición que asumió Criterio frente al divorcio tuvo dos características distintivas. En primer lugar, la revista le brindó escasa atención al tema durante los dos primeros años del gobierno de Alfonsín. Si bien en 1984 publicó un estudio sociológico y estadístico sobre las separaciones en la Argentina elaborado por investigadores de la Universidad Católica, ${ }^{31}$ la primera nota que concretamente se refirió a la discusión de una futura ley de divorcio se publicó recién en 1986, o sea cuando el debate entraba en su etapa más álgida. Esta ausencia relativa se podría comprender por el hecho de que Criterio no era una revista abocada exclusivamente a temas de actualidad y ponía mayor énfasis en temas de cultura, arte, teología, etc. Sin embargo, si bien se trata de una revista amplia en cuanto a contenidos, siempre hubo un espacio importante para abordar cuestiones de política nacional, la situación económica, la revisión del pasado reciente o la política cultural del gobierno. En este marco, no sería arriesgado interpretar la actitud prescindente frente al divorcio en términos de una decisión editorial que, indirectamente, desafió la pretensión de la jerarquía de imponer una agenda a los católicos.

En segundo lugar, el otro rasgo característico del posicionamiento que asumió Criterio fue una preocupación por distinguir entre las concepciones propias en relación con el divorcio -que eran contrarias al mismo en razón de una concepción cristiana de la familia- y la necesidad de debatir sobre el tema. Para Criterio el divorcio era un mal, sobre eso no había dudas en la revista, pero, tomando distancia de las posiciones "de barricada" que predominaban, se consideró que, en el contexto de una sociedad plural y ante la existencia de un problema concreto -como era la cantidad de matrimonios que vivían separados de hecho-, era imprescindible que el legislador interviniera.

Como se podrá presumir, Criterio no mostró ninguna intención de sumarse a la campaña organizada por Ogñenovich y sólo se ocupó del divorcio cuando este alcanzó un lugar destacado en la agenda política. Además, puso de manifiesto que al interior del catolicismo era un tema controvertido e incluso dio cuenta de las diferencias que se manifestaban entre los obispos. Cuando recurrió a citas de autoridad para respaldar sus posicionamientos, tuvo en cuenta documentos del episcopado español, mucho más tolerante frente al divorcio que sus pares argentinos. En este sentido, los obispos españoles sentaron una posición en 1977 que no sólo influyó en Criterio sino que también fue parte fundamental en la argumentación del diputado democristiano Carlos Auyero durante el debate legislativo de 1986. En el tramo más importante del documento episcopal citado por Criterio, los obispos españoles sostuvieron:

(...) si se planteara en un futuro la propuesta de una legislación civil que admitiera el divorcio y la legitimación de nuevas nupcias de los divorciados, los católicos tendrian que adoptar una línea de conducta coherente conforme a las exigencias de la propia fe. Esto no significa que el legislador esté obligado siempre a elevar a la categoría de norma legal todo lo que es una exigencia ética o que deba reprimir con medidas legales todos los males de la sociedad. La tutela de ciertos bienes y la exclusión de males mayores pueden originar un conflicto de valores, ante el cual el gobernante ha de poner en juego la prudencia politica en orden al bien común, que, si no puede prescindir de los valores éticos, tampoco debe desconocer la fuerza de las realidades sociales. ${ }^{32}$

Si esta era la perspectiva que Criterio encontraba adecuada para los católicos argentinos, nada le podía resultar más errado que el desempeño de Ogñenovich al frente dela Secretaría para la Familia durante el debate del divorcio:

No una, sino varias veces ha recurrido al estilo panfletario de las publicaciones nacionalistas de la década del cuarenta para atacar a los que no piensan como él. No nos interesa discutir ahora afirmaciones suyas harto discutibles, como la amenaza de que los diputados que aprueben el divorcio pueden sufrir sanciones canónicas, o que "ningún católico en conciencia puede votar a ninguno de estos legisladores". Lo que nos preocupa es que la Iglesia sea identificada con una voz que no se expresa con la ponderación, el equilibrio y la caridad que los fieles espera de sus pastores. ${ }^{33}$

La revista presentó un análisis del debate parlamentario rico en matices. En primer término, con respecto al proyecto aprobado por los diputados reclamó modificaciones que restringieran la opción por el divorcio 
vincular. Entendían que el proyecto consensuado por los legisladores de distintos bloques era demasiado permisivo. Esta observación no implicaba rechazar de plano la inclusión del divorcio ya que, en definitiva, para los católicos lo realmente importante era reforzar aquellos valores que podían consolidar el matrimonio. ${ }^{34}$ Luego, incluyó la opinión del Dr. José Carreras, juez civil de la Capital Federal, quien hizo eje en la cuestión de los hijos de los matrimonios fracasados. En su abordaje tampoco cuestionó la nueva normativa y reflexionó sobre la necesidad de que el juez minimizara los efectos de una separación. ${ }^{35}$ Finalmente, Criterio le dedicó un análisis específico al debate llevado a cabo por los legisladores. Allí consideró que los católicos se habían dejado arrastrar "a esa discusión ruidosa y estéril" sin producir "propuestas constructivas y realistas que tocaran el fondo de la cuestión en lugar de aparecer en una posición puramente negativa". ${ }^{36}$ En esta lectura hubo un claro respaldo a las propuestas del democristiano Carlos Auyero, sobre las que volveremos en el apartado siguiente.

Poco después, cuando las tensiones se profundizaron a partir de la mencionada recomendación de la Comisión Permanente de la CEA para que se sancionase a los legisladores católicos que habían votado favorablemente el divorcio, Criterio asumió una posición de claro rechazo:

Con ánimo de corrección fraterna, nos parece parte del ejercicio de una opinión pública necesaria a la sociedad y a la Iglesia misma hacer saber nuestro desacuerdo con la "sugerencia" que autoridades episcopales hicieron a los obispos en general -y algunos siguieron- respecto de la votación positiva de diputados católicos en el debate parlamentario sobre la legislación del divorcio y la familia. El divorcio no es un bien sino un mal. Pero al mismo tiempo es preciso distinguir entre el hecho y la legislación [...] para introducir cierto orden en el desorden, para atenuar sus consecuencias. El legislador que, profesando la fe católica, votó por lo que lepareció en conciencia la ley menos injusta, y el que en el futuro, en el senado, procure su perfeccionamiento [...] no nos parece un "pecador público", entre otras razones porque no advertimos dónde está, en rigor, la actitud y el comportamiento pecador.

En definitiva, el episodio en cuestión "no conviene al difícil ejercicio de la autoridad no autoritaria, que tome en cuenta la difícil experiencia de una sociedad que quiere ser democrática". ${ }^{37}$

\section{La revista Cabildo: la denuncia de la complicidad de los católicos}

El recorrido por las páginas de Cabildo pone en evidencia que la jerarquía católica fue interpelada de manera recurrente y, en general, en tono sumamente crítico. La lucha entablada por Cabildo por restaurar un catolicismo medieval, hispanista, preconciliar implicaba cuestionar, muchas veces explícitamente, a la jerarquía -o a los obispos que ejercían la conducción en las instancias formales de la CEA-y a sus teólogos de referencia, en la medida en que entendían que ahí había que buscar a los responsables de la derrota del proyecto de "nación católica".

Cabildo vivió el retorno de la democracia con gran desazón porque significaba el fracaso del proyecto dictatorial por el que había apostado. ${ }^{38}$ En consecuencia, asumió una oposición absoluta y sin concesiones al gobierno de Alfonsín, al que rechazaba no sólo porque era el retorno de la "soberanía del número" sino también por su asociación a la socialdemocracia europea. El tema del divorcio, en este sentido, condensó muchas de las críticas más beligerantes en la medida en que fue la confirmación de sus peores profecías. La revista manifestó desde temprano un rechazo militante a la posibilidad de aprobar el divorcio porque, desde su perspectiva, negaba el orden natural instaurado por Dios, actitud propia de un gobierno de izquierda o "socialdemócrata". La clave para entender tal actitud había que buscarla en los intelectuales que asesoraban al presidente, responsables de la elaboración de un plan destinado a borrar la influencia de la religión católica en la sociedad argentina. El divorcio era un núcleo, tal vez el más importante, de una estrategia de erosión de la tradición que se combinaba además con el "destape", la política cultural y educativa.

Pero hay algo en Cabildo que resulta más relevante en el recorrido que estamos realizando y es que su prédica en torno a la cuestión del divorcio apuntó con particular vehemencia contra los obispos, atribuyéndoles una actitud poco enérgica. No deja de ser paradójico, aunque no tan novedoso entre algunos 
grupos católicos periféricos, que un actor identificado con la defensa de la tradición y el rechazo al Concilio Vaticano cuestionase tan abiertamente a la jerarquía y aportase, de esta manera, a la construcción de una opinión publica católica.

Para Cabildo la cuestión del divorcio emergió como una preocupación ni bien se avizoró en el horizonte el retorno de la democracia. Instalado el nuevo gobierno,el temor se crecentó y se ensayaron respuestas rápidas. En los números de marzo y abril de 1984, bajo el título "Sí a la familia, no al divorcio. Hablan los pastores", Cabildo publicó numerosas intervenciones de los obispos. ${ }^{39}$ La revista valoró positivamente el documento episcopal que en marzo de 1984 reiteró que "nadie que se llame católico puede al mismo tiempo favorecer que se proyecten disposiciones legales" que afecten la estabilidad del matrimonio; ${ }^{40} \sin$ embargo, no dejó pasar la oportunidad de hacer un reclamo y afirmar que de los obispos esperaban mucho más que un documento escueto -efectivamente incluía ocho puntos en no más de una página-:

Pero esperamos más de nuestra Santa Madre Iglesia. Esperamos, precisamente porque es el momento adecuado. el documento exhaustivo y no sólo la sintesis; las grandes razones dogmáticas y no sólo las cuestiones filosóficas. Las penas y castigos a los apóstatas que siembran la confusión y el escándalo autotitulándose "católicos" y propiciando el divorcio u otras inmoralidades [...] Esperamos la admonición, la condena y el Index. La disciplina y el rigor, la corrección severa y la enmienda rápida, llamando a los culpables por su nombre. ${ }^{41}$

Pronto se puso en evidencia que las expectativas de Cabildo no iban a encontrar respuestas en un Episcopado que, como vimos, hacía equilibrio entre sus diferentes líneas internas para mantener consensos mínimos. Para Cabildo, la cuestión no era únicamente enfrentar la campaña en favor del divorcio sino la democracia in toto. Esta diferencia sustantiva se fue explicitando hasta alcanzar su máximo nivel a lo largo de 1986. Cabildo comprendió que la jerarquía estaba más dispuesta a negociar, incluso en una cuestión como la del divorcio, que a enfrentar al "régimen socialdemócrata". En estos términos, todas las iniciativas que desarrollaron los obispos, o muchos de ellos, frente al divorcio, fueron interpretadas como gestos inocuos y forzados destinados a disimular la comodidad que los prelados encontraban en el espacio reservado para ellos en la nueva configuración política:

(...) los católicos tendremos que asumir sin vacilaciones la defensa del matrimonio indisoluble y de la familia, que constituye -no es retórica, sólo expresión de una evidente realidad-la célula fundamental de la sociedad. No parecería exagerado esperar que las jerarquias de la Iglesia hicieran suya esta defensa con tanto entusiasmo -al menos-como el que las embanderó en favor del repudiable tratado de Pazy Amistad con Chile [...] Pareceria sin embargo que los responsables de nuestra Iglesia se han habituado de tal modo a ser promotores de la rendición en todos los campos, que la batalla contra el divorcio no constituirá una excepción a tan nefasta costumbre. ${ }^{42}$

En abril de 1986 Antonio Caponnetto, uno de los referentes de Cabildo, sostuvo que, si bien se habían escuchado voces de laicos y pastores que eran "apologéticas, rectificadoras, desmitificantes y docentes de la recta doctrina", era hora de "promover otra reacción." ${ }^{33}$ Reclamó a los católicos, en particular a la jerarquía, una movilización activa en defensa de la fe, lo que suponía también la defensa de la patria. Le apuntó al "cobarde, anodino, simulador, complaciente, tibio" que, fuera quien fuera, debía ser despreciado públicamente. $^{44}$

En relación conla movilización a la Plaza de Mayo en julio de 1986, la revista señaló algunos aspectos positivos, pero también reprodujo las críticas a "vastos e importantes sectores eclesiásticos, empezando por obispos como Laguna, Casaretto", ${ }^{45}$ y a quienes se posicionaron frente al acto "en función de la interna episcopal". ${ }^{46}$ La revista se lamentó de que mientras las "usinas marxistas de la guerra contracultural y sus socios liberales" pusieron "toda la carne en la parrilla [...] los hombres de Iglesia, No." ${ }^{47}$ Para Cabildo, los obispos "fueron a media máquina. Poniendo piedras en el camino. Enfriando. Que se queme Ogneñovich solito". ${ }^{48}$ En este marco, hablaron de una iglesia "vegetante" que arrastraba años de "componenda, de renuncios", 
acostumbrada a "la sensiblería edulcorada, al contubernio, a bajar todas las banderas para mantener una vaga referencia al 'amor', así en general, invocado por quinceañeras lánguidas” ${ }^{49}$ En síntesis:

Una cosa es cantar pavadas tomaditas de la mano y otra es enfrentar a las furias desencadenadas del infierno. Ese clericalismo que, desde hace mucho, desde antes del Concilio, por cierto, persiguió a Castellani, adulteró con los liberales, fornicó con el marxismo, no puede defendernos del divorcio. Ni de nada. No sirve. Ha fracasado [...] Quiera Dios que tantos que fueron a la Plaza, que vieron pasar la Virgen, que se sienten agredidos y golpeados, despierten del letargo. Que cerremos filas en torno a los pastores de verdad, esos que no se escapan cuando viene el lobo. Que entendamos el combate en toda su dimensión. Que la dureza de la realidad nos despabile, como el viento frío de ese sábado en la Plaza. Esto recién empieza. ;Viva la Virgen! ;Viva la familia! ;Viva la Patria! 50

Una vez que la Cámara de Diputados le dio media sanción al divorcio, que tal como señalamos se logró con holgura, la sensación de derrota ganó el espíritu de los discursos de los católicos tradicionalistas. En Cabildo se impuso la identificación de los responsables de la derrota y allí apareció la "Iglesia postconciliar", objeto siempre impreciso, como la gran culpable. Una Iglesia que, según Cabildo, "calló cuando debía hablar, tartamudeó cuando se esperaba su palabra entera sin cortapisas". Era una Iglesia que frente a los desafíos que imponía el retorno de la democracia no había asumido una posición enérgica y que, por el contrario, había priorizadola búsqueda de "soluciones de compromiso como acercando posiciones, como si la verdad fuera el resultado de acuerdos y de síntesis." ${ }^{\text {1 }}$

El énfasis de la crítica no se puso principalmente en quienes se oponían en forma explícita al divorcio sino en aquellos que "habiendo asumido una primera actitud de activa oposición, transaron luego o se llamaron a silencio". La revista se preguntaba si estos obispos no habían privilegiado "el valor de la unidad del Episcopado -con cerril sentido disciplinario- en menosprecio del valor de la enseñanza de Cristo" ${ }^{52}$ Si bien la sanción a los diputados católicos que habían votado el divorcio fue muy bien recibida, también se volvió a reclamar por medidas más enérgicas. Mientras que para Cabildo este hecho era, apenas, una buena decisión que debía ser profundizada, para los obispos fue un punto de quiebre que expresó la necesidad de buscar acuerdos y abandonar la intransigencia representada por Ogñenovich.

\section{La Democracia Cristiana y el Divorcio}

En los primeros años del gobierno de Alfonsín las cuestiones referidas a la legislación familiar recibieron atención de parte de los dirigentes democristianos, aunque no hubo consensos extendidos. Desde su fundación en 1954, en la Democracia Cristiana convivieron líneas internas unidas por coincidencias generales -como la importancia de la democracia, la legitimidad de los disensos, la validez de la Doctrina Social o el influjo de pensadores como Maritain o Mournier- pero que se diferenciaban profundamente en torno a otros temas, como la relación con los diferentes gobiernos, la posición con respecto al peronismo o sobre los vínculos que deberían mantenerse con la jerarquía de la Iglesia (Cerro, 1983; Parera, 1986). Tanto las coincidencias como las diferencias explican que su historia esté jalonada por desgranamientos y recomposiciones. Como reconocieron algunos de sus dirigentes más importantes, el partido había cosechado más éxitos en la formación de cuadros dirigentes que en la construcción de una alternativa de poder. ${ }^{53}$

En la coyuntura que estamos analizando, tal como señaló Marcela Ferrari (2017), la tendencia se mantuvo, más allá de que se modificaron los motivos de las divergencias. El debate del divorcio, justamente, generó discrepancias dentro del partido e, incluso, surgieron matices entre dirigentes de una misma línea interna. Así, por ejemplo, poco antes de las elecciones de 1983, en la Convención Nacional del partido Francisco Cerro sostuvo que eran "el partido de la familia" aunque se apresuró a aclarar que su defensa del "matrimonio indisoluble” y su condena al divorcio no se debía a una determinada confesión religiosa. Para quien fuera candidato a presidente, el partido defendía el "matrimonio monogámico e indisoluble" porque era "el único compatible con la libertad y la dignidad de la persona humana” (citado en Parera, 1986, T.I: 416). Asimismo, la Plataforma Electoralde 1983 propuso preservar "la institución familiar fundada en el matrimonio y la 
indisolubilidad del vínculo conyugal". En la misma propuesta se incluyó la "patria potestad compartida” y la "igualación delos derechos hereditarios a los hijos habidos de uniones de hecho estables". 54

Luego de consumado el triunfo de Raúl Alfonsín, algunos dirigentes del PDC se incorporaron al nuevo gobierno en ámbitos directamente relacionados con la problemática familiar. Enrique de Vedia asumió el cargo de Secretario de Desarrollo Humano y Familia y contó con Horacio Sueldo y Carlos Eroles como asesores. Este último fue, además, Director Nacional del Menor entre 1985 y 1986 (Parera, 1986, T. II: 275).

La modificación en el régimen de patria potestad fue la primera reforma sustancial introducida en la legislación familiar y fue un proyecto elaborado por la secretaría que dirigía De Vedia. En este punto no hubo rispideces dentro del PDC porque, como señalamos, era una propuesta incluida en la plataforma partidaria. Sin embargo, las tensiones fueron en aumento a medida que algunos dirigentes se expresaron favorables también a la implementación del divorcio. En cierta medida, mientras que para los sectores del partido más conservadores la modificación del régimen de patria potestad era un punto de llegada, para aquellos que se habían sumado al gobierno era el inicio de una serie de cambios necesarios para democratizar las relaciones familiares. Entre ellos se encontraban Néstor Vicente y Augusto Conte, pertenecientes a Humanismo y Liberación, corriente interna que se encontraba disputando la conducción del partido desde posiciones que la acercaban a la izquierda del espectro partidario (Ferrari, 2017). El caso de Conte levantó cierta polvareda porque era, además, el único legislador nacional del partido. Las tensiones internas a raíz de esta cuestión fueron en aumento y en el verano de 1985 el plenario de la Junta Nacional del Partido decidió desautorizar a Conte, entre otras cuestiones, porque había atacado "a personalidades de la jerarquía católica" y porque "contrarió la posición del partido en materia de matrimonio y familia" (citado en Parera, 1986, T. II: 475). Una declaración de Horacio Sueldo, histórico dirigente democristiano convocado con el objetivo de apaciguar la interna partidaria, expresó con justeza algunos de los ejes del conflicto. Allí habló de "la ratificación de ortodoxias tan incompatibles con la natural laicidad de la tarea política, como desequilibradas en la apreciación de ciertas conductas clericales" (Parera, 1986, T. I: 476).

Poco después fue Enrique de Vedia quien sostuvo que era muy probable que durante 1986 el Congreso aprobara el divorcio y agregó, desafiando los argumentos en los que tanto había insistido Ogñenovich, que la nueva legislación de "ninguna manera será para la disolución nacional o social, sino el reconocimiento debido a las parejas que no han podido encontrar un núcleo familiar definitivo". El dirigente democristiano y funcionario del gobierno interpretó que "el principal escollo para este debate está determinado, en gran medida, por una especie de anquilosamiento al que la sociedad argentina fue llevada, a veces por problemas de inmovilismo social y político, y otros a que nos sometieron las dictaduras". 55

El cardenal Aramburu, arzobispo de Buenos Aires y uno de los más activos en la campaña contra el divorcio, recogió el guante y en declaraciones dirigidas especialmente a De Vedia sostuvo:

Ante la campaña que se está promoviendo, dirigida a introducir el divorcio vincular en nuestro ordenamiento jurídico, a la que ban cedido, lamentablemente, algunas personas que se dicen católicas, queremos reafirmar para nuestros fieles y a todos nuestros conciudadanos que el matrimonio es indisoluble. Sin ello la estabilidad de la familia careceria de su factor primordial. ${ }^{56}$

Según consignó la revista Esquiú, otro "alto funcionario de la Iglesia” se manifestó contra el dirigente democristiano al sostener que era "hora ya de que ciertos sedicientes católicos se desprendan de esa etiqueta ya que su postura no coincide con la doctrina de la Iglesia Católica”. Según la misma publicación, en "medios eclesiásticos" se había enfatizado que "no es posible que el doctor De Vedia, por querer favorecer a una minoría de matrimonios mal avenidos, pretenda destruir toda la estructura de la institución familiar". ${ }^{57} \mathrm{La}$ revista Cabildo, sin medias tintas, calificó a Sueldo, Conte y Auyero como dirigentes "democretinos" ${ }^{58}$

La intervención de Conte en el Congreso cuando se debatió la modificación del régimen de patria potestad no apaciguó los ánimos. Conte defendió en forma entusiasta el proyecto oficial subrayando los aportes de De Vedia y Sueldo. Luego les apuntó directamente a aquellos obispos y grupos católicos que con mayor firmeza 
denunciaban las “novedades" de la democratización. A estos sectores los interpeló con un discurso en el que el componente religioso ocupó un lugar central:

¿Qué hay de los valores cristianos? ¿De qué otro modo puede entenderse la calidad del hijo extramatrimonial sino en su sustancial condición de hijo de Dios, igual a todos? ¿Quién no recuerda el Evangelio cuando Jesús, al lado de la prostituta, la levanta a su nivel-al de Jesis hijo de Dios-y simplemente le formula una exhortación para que trate de no pecar? Si el hijo de Dios trata asi a una prostituta, ¿puede acaso nuestra sociedad-con la calidad de valores que tenemos hoy por delante-discutir siquiera acerca del hijo extramatrimonial, esa criatura hija de un traspié o de un pecado en que no tuvo nada que ver?59

El accionar de esos sectores "católicos más tradicionales y sectores del episcopado" que auguraban la "destrucción de la familia" fue caracterizado por Conte como "relampagueos fascistas" ${ }^{60}$

Este debate resultó importante por dos razones. En primer lugar, porque introdujo una modificación que, desde la perspectiva de quienes se opusieron, implicaba un cambio sustancial en el modelo de familia vigente hasta entonces. En segundo lugar, porque a nadie escapó que inauguraba una pretensión reformista de los legisladores que, en el ámbito de la familia, tendría como próxima escala el divorcio.

En 1986, cuando se comenzó a debatir el divorcio, se había incorporado al Congreso Carlos Auyero, electo por el frente encabezado por el peronismo renovador (Ferrari, 2018). A pesar de que Conte y Auyero pertenecían a Humanismo y Liberación, sus posiciones ante el divorcio fueron diferentes. Augusto Conte no tuvo participación activa en el debate legislativo, aunque sí votó afirmativamente el proyecto mayoritario que incluía el divorcio vincular. A pesar de que, como señalamos arriba, Conte se había manifestado tempranamente a favor, no parece haber sido una decisión sencilla. Según el relato de uno de sus asesores, Roque Bellomo, a la hora de la votación el legislador porteño tuvo dudas y evaluó ausentarse del recinto. ${ }^{61}$ Es probable que las dudas estuvieran motivadas por el hecho de que el único proyecto alternativo había sido presentado, precisamente, por Auyero, quien sí tuvo un rol protagónico en el debate.

En su intervención, Auyero partió de dos definiciones de suma importancia. En primer lugar, sostuvo que se opondría categóricamente "al inmovilismo que en esta materia pretende congelar una legislación casi centenaria". ${ }^{62}$ En segundo lugar, aclaró que no pretendía imponer sus convicciones personales "al conjunto de una sociedad pluralista que vive en un marco democrático". ${ }^{63}$ Luego sintetizó su propuesta y resaltó que con ella establecía "una ampliación muy grande del régimen de anulaciones y la consecuente producción de la rehabilitación nupcial”. Así planteada, su propuesta parecía un camino alternativo para llegar al mismo destino. El proyecto incluía, además, "normas tendientes a la protección y promoción de la familia en materia económica, social, cultural, y aun espiritual" y preveía "la creación de juzgados de familia[...]con un amplio régimen de apoyo técnico para las instancias de prevención y conciliación de conflictos”. El proyecto iba explícitamente más allá del divorcio y se presentaba como una reforma integral; sin embargo, no había dudas de que lo que acaparaba la atención de la sociedad era la posibilidad de la rehabilitación nupcial.

En cuanto al celo puesto por Auyero en distinguir la función social del legislador, proyectada a la búsqueda del bien común en una democracia pluralista, de sus convicciones religiosas, que en el esquema presentado pertenecían a la esfera privada, es posible afirmar que no fue propiedad de todos los legisladores. Si entre quienes se opusieron al divorcio fue bastante recurrente la invocación del respeto de los valores y principios que entorno a la familia enseñaba la Iglesia, más llama la atención que varios diputados buscaran respaldar su apoyo al divorcio recurriendo a conceptos religiosos e incluso pretendiendo actuar como intérpretes de los textos bíblicos (Fabris, 2011).

Auyero fundamentó esa diferenciación, que tanto molestaba a la revista Cabildo y a los sectores integristas, en aquel documento del Episcopado español que había destacado la revista Criterio y subrayó que el legislador no podía ignorar "la fuerza de las realidades sociales". Era esa fuerza de las realidades sociales, siguiendo con su argumentación, la que había motivado su propuesta centrada en la ampliación del "régimen de anulabilidad”. Para Auyero, no se trataba de que pudieran "existir leyes contra la moral" sino de que "no necesariamente 
todo lo que es moral debe ser obligado por la ley", ya que "hay un ámbito extenso de la moral que queda sujeto a la conciencia de cada uno de nosotros". Por lo tanto, sostuvo que

apelando a mis propias convicciones, tengo para mi un modelo de familia, un ideal de convencimiento con respecto a la perdurabilidad del vinculo conyugal. Para mi y fundamentalmente para mi fe quiero no la práctica coactivade la pretensión de imponerla por la ley al conjunto de la sociedad, sino la posibilidad de que se me permita ejercitar mi fe con libertad. ${ }^{64}$

Entendemos que la intervención de Auyero ofrece algunas aristas interesantes para reflexionar sobre el vínculo siempre complejo entre religión y política. En concreto, vistas en conjunto, la intervención en el debate y la propuesta presentada reflejan cierta tensión entre aquellos ámbitos. Lo entendemos así porque mientras que, en la intervención, como señalamos, no hubo referencias a la doctrina de la Iglesia y Auyero se preocupó por trazar una distinción clara entre religión y política, su propuesta pareció reflejar una solución de compromiso que no obviaba las expectativas de la Iglesia. En su propuesta, los problemas que se derivaban de la imposibilidad de contraer nuevas nupcias no se resolvían a través de la incorporación del divorcio vincular, como en el proyecto de la mayoría, sino a partir de la extensión de las nulidades matrimoniales. Se trató de una propuesta cuyo resultado podía ser la construcción de consensos entre las posiciones más enfrentadas, pero que naufragó ante la mirada desconfiada de unos y de otros. Para quienes promovían la aprobación del divorcio, podía pasar por una falta de decisión ante el influjo de la Iglesia. Para los sectores antidivorcistas, bien representados en su versión extrema por Cabildo, no era sino una traición de quienes se proponían negociar con la modernidad sacrificando los valores que históricamente había defendido la Iglesia. Para ellos, la actitud de los dirigentes democristianos era peor aún que la de los divorcistas.

\section{Conclusión}

El divorcio es comúnmente definido como uno de los grandes logros del proceso de reconstrucción democrática iniciado en 1983 en el ámbito familiar y es concebido como un eslabón fundamental en la dinámica de ampliación de derechos. También se lo ha identificado como un símbolo de la lucha anticorporativa que habría llevado a cabo Raúl Alfonsín y, relacionado con todo lo anterior, como un paso importante en la demarcación de limites más nítidos entre religión y política. Si bien es evidente que el divorcio actuó en estas direcciones -más allá de que resulte complejo medir su grado de incidencia-, hay aspectos que quedaron un tanto olvidados. En este artículo señalamos, en primer término,que se obvió que la aprobación de la nueva legislación incluyó ciertas continuidades de las prácticas que regían las relaciones entre la Iglesia y el poder político- y, en segundo término, que el catolicismo no se movió como un bloque monolítico en respuesta al llamamiento de sus obispos.

Hemos propuesto un recorrido que permitió dar cuenta, recurriendo sólo a algunos ejemplos de un universo bastante más amplio, de la diversidad que anidaba en el catolicismo y de los cuestionamientos a las posiciones de los obispos que podían encontrarse aloptarporotraescala de análisis. Pudimos mostrar muchas de lastensiones que emergieron deteniéndonos en el caso de la prensa católica y de los dirigentes y legisladores democristianos.

El abordaje de la prensa expone un universo bastante plural. Desde una revista como Esquiú, que fue un apoyo importante en la campaña articulada por el Episcopado y se movió en consonancia con las decisiones de los obispos, hasta una publicación como Cabildo, que desde una posición crítica rechazó no sólo el divorcio sino también la estrategia desarrollada por los mismos obispos. Criterio, el otro caso abordado, al igual que Cabildo se distanció de la CEA, aunque lo hizo en dirección contraria a la asumida por la revista referente del tradicionalismo católico. Criterio rechazó las reacciones más intempestivas de los obispos, en particular de Ogñenovich, y si bien consideraba el divorcio como un mal, lo hizo desde una posición que diferenciaba lo 
político de lo religioso. Esta diferenciación resultaba, sino novedosa dada la trayectoria de Criterio, sí relevante en un universo católico que alimentaba visiones integristas en el tema familiar.

En cuanto a la dirigencia democristiana, la intervención de Carlos Auyero, el más activo en el debate, hace visible la búsqueda de una síntesis -que también, a su manera, propuso Criterio-de un nuevo consenso que suponía, necesariamente, que las concepciones religiosas debían sostenerse en un marco político-cultural novedoso para la Argentina. El aspecto consensual implícito en esta búsqueda era el eje de las críticas de quienes percibían un ataque a la identidad de los católicos.

Ese catolicismo democrático, "moderno", que podían representar Auyero o Criterio, era bien recibido por aquellos sectores políticos que se asumían protagonistas de los cambios que vivía el país y que aspiraban al destierro de una cultura política autoritaria. Sin embargo, cuando las tensiones entre la Iglesia y la clase dirigente asumieron rasgos virulentos, la posición de quienes buscaban la síntesis no dejó de ser endeble y aislada.

\section{LISTA DE REFERENCIAS}

Acha, O. (2001). Las percepciones de género según el catolicismo argentino plasmadas en Criterio (1928-1943). Signos Históricos, 5, 141-173.

Bianchi, S. (2001). Catolicismo y peronismo. Religión y politica en la Argentina, 1943-1955. Tandil: IEHS.

Bonnin, J. E. (2006). Iglesia y democracia. Táctica y estrategia en el discurso de la Conferencia Episcopal Argentina (1981-1990)(Tesis de Maestría). Buenos Aires: Universidad de Buenos Aires.

Borrelli, M. y Lanfranco, F. (2012). “Otra intromisión que no debió permitirse”: la revista Cabildo frente a la visita de la Comisión Interamericana de Derechos Humanos a la Argentina en 1979. Diálogos, 84, 1-18.

Caimari, L. (1995). Perón y la Iglesia católica. Religión, Estado y sociedad en la Argentina (1943-1955). Buenos Aires: Ariel.

Cerro, F. (1983). Quées el Partido Demócrata Cristiano. Buenos Aires: Sudamericana.

Cersósimo, F. (2014). El tradicionalismo católico argentino: entre las fuerzas armadas, la Iglesia católica y los nacionalismos. PolHis, 14, 341-371.

De Ruschi Crespo, M. I. (1998). Criterio, un periodismo diferente: génesis y fundación. Buenos Aires: Grupo Editor Latinoamericano.

Di Stefano, R. (2011). Por una historia de la secularización y de la laicidad en la Argentina. Quinto Sol, 15, 1-31.

Esquivel, J. C. (2004). Detrás de los muros. La Iglesia católica en tiempos de Alfonsín y Menem (1983 - 1999).Buenos Aires: UNQ.

Esquivel, J. C. (2010). Notas sobre la laicidad en Argentina. Debates do NER, 18, 149-171.

Ezcurra, A. M. (1988). Iglesia y transición democrática. Ofensiva del neoconservadurismo católico en América Latina. Buenos Aires: Puntosur.

Fabris, M. (2011). Iglesia y democracia. Avatares de la jerarquía católica en la Argentina post autoritaria (1983-1989). Rosario: Prohistoria.

Fabris, M. (2012). La prensa católica y el horizonte democrático. La revista Esquiú, el gobierno militar y la Iglesia en el contexto transicional, 1981-1983. Actas electrónicas del IV Simposio Internacional sobre Religiosidad, Cultura y Poder. Buenos Aires, Argentina: GERE - Facultad de Filosofía y Letras de la Universidad de Buenos Aires.

Fabris, M. (2013). De El Pueblo a Esquiú. Modernización y regresión conservadora frente a la crisis de la prensa católica. Itinerantes, 3, 153-170.

Fabris, M. (2015). Revisar el pasado reciente. Las revistas Criterio y Esquiú y la cuestión de los derechos humanos, 1981-1985. Quinto Sol, 3, 1-21.

Fabris, M. (2018). La Democracia Cristiana y la Iglesia durante la última dictadura. Catolicismo, política y derechos humanos. Estudios Sociales, 54, 143-168. 
Fabris, M. (2019) Criterio entre la dictadura y la democracia. Su mirada sobre los desafíos a la Iglesia en un contexto transicional. En M.Lida, M. y M. Fabris (Coord.). La revista Criterio y el siglo XX argentino (pp. 191-212). Rosario: Prohistoria.

Ferrari, M. (2017). La Democracia Cristiana argentina durante la dictadura cívico-militar y la transición temprana (1976-1985). Revista Historia, 1, $49-77$.

Ferrari, M. (2018). Democracia Cristiana, Partido Justicialista y política de frentes. El FREJUDEPA en perspectiva histórica. Boletín del Instituto de Historia Argentina y Americana Dr. Emilio Ravignani, 48, 121-153.

Giordano, V. (2014). De "ciudadanas incapaces" a sujetos de "igualdad de derechos": Las transformaciones de los derechos civiles de las mujeres y del matrimonio en Argentina. Sociedad, 33,1-20.

González, M. (2012). Esquiú-Color ante el proceso de apertura política (1981-1982): de la democracia tutelada a la reconciliación nacional. En J. Saborido y M. Borrelli (Comp.).Voces y Silencios. La prensa argentina y la dictadura militar (1976-1983) (pp. 251-274). Buenos Aires: Eudeba.

Hervieu-Léger, D. (2004). El peregrino y el convertido. México: Ed. Helénico.

Lida, M. (2012). La rotativa de Dios. Prensa católica y sociedad en Buenos Aires: El Pueblo 1900-1960. Buenos Aires: Biblos.

Lida, M. y Fabris, M. (Coord.) (2019). La revista Criterio y el siglo XX argentino. Religión, cultura y politica. Rosario: Prohistoria.

McAdam, A., Sukup, V. y Katiz, C. (1999). Raúl Alfonsin: la democracia a pesar de todo. Buenos Aires: Corregidor.

Muiño, O. (2013). Alfonsín. Mitos y verdades del padre de la democracia. Buenos Aires: Aguilar.

Orbe, P. (2009). Entre mitines y misas: La revista Cabildo y la red de sociabilidad nacionalista católica (1973-1976). V Jornadas de Historia Politica, Bahía Blanca, Argentina. Recuperado de http://www.historiapolitica.com/dat os/biblioteca/orbe_jiv.pdf

Parera, R. (1986). Los democratacristianos argentinos. Testimonios de una experiencia politica. Tomo I. Buenos Aires: Ed. Leonardo Buschi.

Pecheny, M. (2010). Parece que no fue ayer: el legado político de la Ley de Divorcio en perspectiva de derechos sexuales. En R. Gargarella, V. Murillo y M. Pecheny (Comp.), Discutir Alfonsin (pp. 93-123). Buenos Aires: Siglo XXI.

Rapalo, M. E. (1990). La Iglesia católica argentina y el autoritarismo político: la revista Criterio 1928-1931. Anuario IEHS, 5, 51-70.

Rodríguez, L. (2011). Los nacionalistas católicos de Cabildo y la educación durante la última dictadura en Argentina. Anuario de Estudios Americanos, 68, 253-277.

Saborido, J. (2011). "Solo la Revolución Nacional salvará a la Patria”. La Revista Cabildo y el ideario del nacionalismo católico en las décadas de 1970 y 1980. En F. Mallimaci y H, Cuchetti (Comps.), Nacionalistas y nacionalismos. Debates y escenarios en América Latina y Europa (pp. 31-62). Buenos Aires: Editorial Gorla.

Saborido, M. (2013). "De retorno a una Argentina nueva”. Esquiu Color y el Golpe de Estado del 24 de marzo de 1976. RIHUMSO, 4, 1-14.

Zaccari, V. (2004). Iglesia y dictadura. El objeto discursivo "Latinoamérica" en los editoriales de Esquiú Color". Congreso Internacional Politicas Lingüisticas e integración regional, Buenos Aires, Argentina: Facultad de Filosofía y Letras de la Universidad de Buenos Aires.

Zaccari, V. (2005). "La crítica al cine en Esquiú Color". VI Congreso Internacional "Discursos Críticos". Buenos Aires, Argentina: Asociación Argentina de Semiótica.

Zanca, J. (2013). Cristianos antifascistas. Buenos Aires: Siglo XXI.

\section{Notas}

1 Este trabajo se realizó en el marco de un proyecto en la Carrera de Investigador Científico de Conicet.

2 En el contexto de los debates del Concilio Vaticano II la revista mantuvo altos índices de circulación. En el año 1962, por ejemplo, el promedio de ejemplares por edición fue de 74.500. Durante la década de 1970 hubo un marcado descenso 
y en 1974 y 1975 alcanzó los índices de circulación más bajos. Durante los primeros tres años de la dictadura militar se produjo un repunte notable; sin embargo, a partir de 1980 las ventas volvieron a caer. En vísperas del retorno democrático el nivel de circulación había descendido a 27.000 ejemplares (Fabris, 2013).

3 Este autor señala que esa doctrina religiosa tradicionalista se caracteriza por: 1) el teísmo político -la omnipotencia de una autoridad ungida por Dios-; 2) el reconocimiento de la existencia de dogmas religiosos inmutables, que trascienden las interpretaciones de cada individuo; 3) la defensa de la continuidad histórica de las comunidades humanas frente a la amenaza de ruptura que constituye la revolución; 4) la consiguiente reivindicación de las "realidades vivas", que por medio de hábitos sociales, usos y costumbres, conforman las sagradas herencias del pasado; 5) la lucha contra la "razón", definida como el factor perturbador que impulsa el principal pecado introducido por la Modernidad: la autonomía del hombre (Saborido, 2011: 46-47).

4 Las entrevistas y notas biográficas incluidas en el libro de Ricardo Parera Los democratacristianos argentinos (1986) ponen en evidencia la centralidad de la Iglesia católica en la formación de los principales dirigentes del partido.

5 Boletín AICA, No 1340, 26/8/1982 y Guia Eclesiástica Argentina 1992, Buenos Aires, AICA, 1992. Esquivel identificó a Ogñenovich como representante de aquello que, en términos típico ideales, define como "eclesiología de la neocristiandad". Esta eclesiología "no renuncia a que la realidad espiritual absorba el mundo de lo temporal” y supone que cualquier "disociación es sinónimo de fractura entre el espíritu y el cuerpo" (Esquivel, 2004: 28). Esto implica, en el ámbito familiar, un rechazo a cualquier intervención del poder político que cuestione un modelo supuestamente inscripto en la naturaleza.

6 Boletín de la Agencia Informativa Católica, No 1399, 10/10/1983, p. 7.

7 En cuanto a los documentos, pueden verse: CEA, Documentos del Episcopado Argentino, 1984. Buenos Aires, Oficina del Libro, Buenos Aires, 1989; Documentos del Episcopado Argentino, 1985. Buenos Aires, Oficina del Libro, 1989; Documentos del Episcopado Argentino, 1986-1987. Buenos Aires, Oficina del Libro, 1989. Las declaraciones fueron reproducidas por los principales periódicos de tirada nacional. Además, el Boletín de laAgencia Informativa Católica publicó las intervenciones de los obispos y, en particular, sus homilías sobre el divorcio fueron compiladas en fascículos. En cuanto a las revistas, como se verá, fue Esquiú la que mayor atención le prestó al tema.

8 El obispo de Villa María Guillermo Disandro le prohibió ejercer el ministerio sacerdotal, sanción que se extendió hasta la década de 1990.

9 Ogñenovich, Emilio. "Hipólito Yrigoyen se opuso al divorcio”, en $A I C A D O C, \mathrm{~N}^{\circ}$ 140, suplemento del Boletín $A I C A$, $\mathrm{N}^{\circ}$ 1431, 24/5/1984, p. 68.

10 Boletin AICA, No 1476, 4/4/1985, p. 6.

11 Clarin, 23/4/1986, p. 39.

12 Boletin AICA, No 1500, 19/9/1985, p. 19.

13 Publicidaddel grupo Familia Argentina dependiente de la Secretaria Episcopal para laFamilia presidida por Ogñenovich, Esquiú Color, $\mathrm{N}^{\circ} 1367,6 / 7 / 1986$, p. 8.

14 Boletin AICA, No 1529, 10/4/1986, p. 11.

15 Esquiu Color, $\mathrm{N}^{\circ} 1366,30 / 6 / 1986$, p. 4.

16 Clarin, 3/7/1986, p. 16.

17 Según Ezcurra, se llevaron a cabo marchas semejantes en catorce de las cuarenta y tres diócesis (1988: 117).

18 Boletin AICA, No 1557, 23/10/1986, p. 5.

19 Clarin, 22/10/1986, p.15.

20 Clarin, 9/11/1986, p. 2.

21 Incluso cuando la Corte Suprema falló habilitando el divorcio a partir de una demanda iniciada por un particular, el obispo de Mercedes se negó a declarar sobre el tema alegando que debía ser la CEA la que se definiera. Clarín, 29/11/1986, p. 14 .

22 Clarin, 5/6/1987, p. 7.

23 Entrevista a Luis Eduardo Luchía Puig, propietario de la revista Esquiú, realizada por el autor en julio de 2011.

24 Esquiú, No1356, 20/04/1986, p. 1.

25 Esquiú, N 1302, 07/04/1985, p. 7.

26 Esquiu, $\mathrm{N}^{\circ} 1317,21 / 07 / 1985$, p. 8.

27 Luchía Puig, Luis E. “Dos años de Alfonsín”, Esquiú, N 1336, 01/12/1985, p. 3.

28 Esquiú, N ${ }^{\circ} 1368,13 / 07 / 1986$.

29 Luchía Puig, Luis E. “Triunfó el trigo sobre la cizaña”, Esquiú, N 1368, 13/07/1986, p. 3 (resaltado en el original).

30 Esquiú, No 1357, 27/04/1986, p. 39.

31 Balián de Tagtachian, Beatriz, De Imaz, José Luis, Marcenaro Boutell, Roberto y Passanante, María Inés. "Matrimonios y divorcios. Un análisis sociológico", Criterio, N 1929, 23/08/1984, pp. 440-447.

32 "La legislación familiar", Criterio, N 1968, 10/07/1986, p. 329.

33 "Iglesia y opinión pública", Criterio, N 1971, 28/08/1986, p. 431. 
34 "La estabilidad del matrimonio", No 1972, 11/09/1986, Criterio, p. 463.

35 Carreras, José, “Padres separados, hijos, tribunales”, Criterio, N 1972, 11/09/1986, pp. 467- 472.

36 Navarro Floria, Juan, "El divorcio en el Congreso", Criterio, N 1972, 11/09/1986, pp. 473-474.

37 "El espacio de los laicos", Criterio, N 1976, 13/11/1986, pp. 610-611.

38 A decir verdad, el entusiasmo con el llamado "Proceso de Reorganización Nacional" duró bastante poco y fue derivando en una crítica a la política económica, cultural e internacional. La llamada "lucha contra la subversión" fue, probablemente, uno de los pocos temas en losque continuó alineada con el régimen militar.

39 Cabildo, $\mathrm{N}^{\circ} 73$ marzo de 1984, p. 15 y Cabildo, $\mathrm{N}^{\circ} 74$, abril de 1984, p. 17.

40 Comisión Permanente de la CEA, "La indisolubilidad matrimonial”. En Documentos del Episcopado Argentino, 1984, Buenos Aires, Oficina del libro, p. 79.

41 "Los obispos y el divorcio", Cabildo, N 76, mayo de 1984, p. 10.

42 Arteaga, Ignacio, "Divorcio: preparando la rendición”, Cabildo, N 95, diciembre de 1985, p. 28.

43 Caponnetto, Antonio, "Los sirvientes de Asmodeo", Cabildo, № 99, abril de 1986, p. 6.

44 Caponnetto, Antonio, "Los sirvientes de Asmodeo", Cabildo, № 99, abril de 1986, p. 7.

45 Justo Laguna y Jorge Casaretto, obispos de Morón y San isidro respectivamente, fueron criticados en forma reiterada en Cabildo. Se los caracterizaba como liberales y como los más cercanos al gobierno en el Episcopado.

46 Miralles, Carlos “Balance del 5 de julio. Luces y sombras”, Cabildo, N 102, julio de 1986, p. 12.

47 Miralles, Carlos "Balance del 5 de julio. Luces y sombras”, Cabildo, N 102, julio de 1986, p. 11.

48 Miralles, Carlos “Balance del 5 de julio. Luces y sombras”, Cabildo, N 102, julio de 1986, p. 11.

49 Miralles, Carlos "Balance del 5 de julio. Luces y sombras”, Cabildo, Nº 102, julio de 1986, pp. 12 y 13.

50 Miralles, Carlos “Balance del 5 de julio. Luces y sombras”, Cabildo, N 102, julio de 1986, p. 13.

51 Riva, Álvaro “La iglesia 'postconciliar' y el divorcio”, Cabildo, N 104, septiembre de 1986, p. 9.

52 Riva, Álvaro “La iglesia 'postconciliar’ y el divorcio”, Cabildo, N¹04, septiembre de 1986, p. 9.

53 Entrevista a Ricardo Parera, realizada por el autor, noviembre de 2017.

54 Plataforma de la Democracia Cristiana, 1983, p. 27.

55 Mizerit, Antonio “¿Católicos y divorcistas?”, Esquiú, 23/04/1986, pp. 4 y 5.

56 Mizerit, Antonio “¿Católicos y divorcistas?”, Esquiú, 23/04/1986, p. 5.

57 Mizerit, Antonio “¿Católicos y divorcistas?”, Esquiú, 23/04/1986, p. 5.

58 Artega, Ignacio, “Divorcio: Preparando la Rendición”, Cabildo, N 95, 12/1985, p. 28.

59 Diario de Sesiones de la Cámara de Diputados, año 1984, Tomo XII, Buenos Aires, Imprenta del Congreso de la Nación 1986, $45^{a}$ Reunión, 6 a Sesión Extraordinaria, 27/03/1985, p. 7487.

60 Diario de Sesiones de la Cámara de Diputados, año 1984, Tomo XII, Buenos Aires, Imprenta del Congreso de la Nación 1986, $45^{a}$ Reunión, 6a Sesión Extraordinaria, 27/03/1985, p. 7489.

61 Entrevista a Roque Bellomo, realizada por el autor, diciembre de 2016.

62 Diario deSesiones de la Cámara de Diputados, año 1986, Tomo V. Reunión 25ª 13/08/1986, p. 3553.

63 Diario de Sesiones de la Cámara de Diputados, año 1986, Tomo V. Reunión 25ª 13/08/1986, p. 3554.

64 Diario de Sesiones de la Cámara de Diputados, año 1986, Tomo V. Reunión 25ª 13/08/1986, p. 3558 